\title{
Screening for family functioning and mental health in adolescents with non-cardiac chest pain: A comparison study for a frequently encountered problem
}

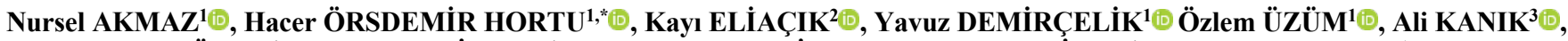

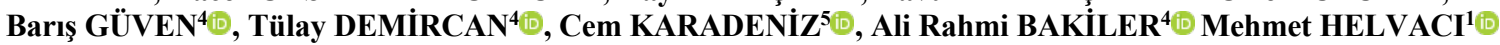 \\ ${ }^{1}$ Department of Pediatrics, İzmir Tepecik Teaching and Research Hospital, İzmir, Turkey \\ ${ }^{2}$ Department of Adolescent Medicine, İzmir Tepecik Teaching and Research Hospital, İzmir, Turkey \\ ${ }^{3}$ Department of Pediatrics, Faculty of Medicine, Katip Çelebi University, İzmir, Turkey \\ ${ }^{4}$ Department of Pediatric Cardiology, İzmir Tepecik Teaching and Research Hospital, İzmir, Turkey \\ ${ }^{5}$ Department of Pediatric Cardiology, Katip Çelebi University, İzmir, Turkey
}

Received: $01.10 .2020 \quad \bullet \quad$ Accepted/Published Online: 30.01.2021 • Final Version: 23.04.2021

\begin{abstract}
Chest pain is highly prevalent in adolescence, represents a considerable burden for health services, and rarely associated with cardiac disease. Since psychosocial factors are related to chest pain there is a need for exploring the accompanying family functioning and mental health problems in adolescents with non-cardiac chest pain. Here, we assessed these determinants in 68 adolescents with non-cardiac chest pain and 68 age and-sex matched control participants using the 4-item Patient Health Questionnaire-4 for a brief screening for anxiety and depression and the Family APGAR Scale to assess the perception of family functioning. Adolescents with non-cardiac chest pain reported more depression, anxiety and experienced impaired family functioning $(\mathrm{p}=0.003, \mathrm{p}<0.001, \mathrm{p}<0.001)$. The results indicated that non-cardiac chest pain is a warning sign of an underlying mental health problem with accompanying family issues and it deserves further psychosocial investigation including anxiety, depression, and impaired satisfaction of the adolescents' family's responsiveness.
\end{abstract}

Keywords: adolescent, anxiety, chest pain, depression

\section{Introduction}

Chest pain in adolescents is one of the common causes of admission to the pediatric outpatient clinics and emergency department (Avison and McAlpine, 1992). Despite this significant burden, the natural history of non-cardiac chest pain in the community has not been clearly explained yet (Bass and Mayou, 2002).

In contrast to its presentation in adults, chest pain in children and adolescents is rarely a sign of cardiac disease (Bass and Wade, 1984). Psychogenic factors are the broadest area of non-cardiac causes of chest pain. Although non-cardiac medical causes (e.g., musculoskeletal, gastrointestinal, asthma) are sometimes identified, the majority of cases (25 to $85 \%$ ) have no clear medical etiology (Avison and McAlpine, 1992; Bekhuis et al., 2015). About half of the children with psychogenic chest pain also have a history of other somatic complaints or have a family member with similar symptoms. Other findings consistent with psychogenic chest pain include stressful life events and sleep disturbances. Kashani, Lababidi, and Jones (1982) have suggested that chest pain can be a physical manifestation of depression in children. Porter, Fein, and Ginsburg (1997) reported similar findings, 22\% of depressed adolescents describing the somatic complaint of chest pain on arrival at the emergency department (Avison and McAlpine, 1992). Non-cardiac chest pain can be established thorough history, physical examination and proper laboratory investigations after all other possible etiologies are ruled out (Cole and Rehm, 1986). Chest pain without any organic reason has been named with different labels such as unexplained, idiopathic, and non-cardiac (Cole and Rehm, 1986).

Since at least half of the new referrals to cardiac outpatient clinics with the presenting complaint of chest pain are found not to have heart disease or other serious physical disorders. Despite a normal expectation of life and physical prognosis, most cases continue to experience symptoms, worry about heart disease, restrict their activities and seek medical help (Eliacik et al., 2017; Demircia and Ekşib, 2018). In the adolescence period, depression appears to be associated with family environments characterized by an absence of supportive and facilitative interactions and, conversely, by elevated levels of conflictual, critical, and angry interactions. The most widely reported finding is that depression is inversely related to the level of support and approval provided by the family 
environment (Eslick et al., 2003; Juli-anne et al., 2000). Therefore, we aimed to screen anxiety, depression besides the patient's satisfaction with his or her family's responsiveness to need in this clinical group.

\section{Materials and methods}

A total of 89 subjects aged 13-18 years were selected sequentially who presented to pediatric outpatient cardiology clinics and diagnosed with non-cardiac chest pain were included in this study. Adolescents who had a chronic disease (gastroesophageal reflux disease, cardiovascular disease, pulmonary disease, etc.) and who were not native Turkish speakers were ruled out from the study. During the survey, 21 adolescents who did not want to participate or have a lack of data were excluded from the study. After the exclusion, 68 participants with chest pain were included in data analysis. The control group comprised of 68 age-and sex-matched volunteer adolescents who visited pediatric cardiology outpatient clinics for pre-participation cardiovascular screening before joining a sports club. The volunteer adolescents were invited to fill the forms including age, sex, Patient Health Questionnaire-4 (PHQ-4) and Family APGAR (Adaptation, Partnership, Growth, Affection, Resolve) Scale. The PHQ-4 is a screening instrument for depression and anxiety for the first step of assessment in patients with medical diseases. The PHQ-4 is an ultra-short screening instrument for depression and anxiety. The items of the PHQ-4 measure core symptoms of depressive disorders (loss of interest, depressed mood) and generalized anxiety disorder (feeling nervous and anxious, difficulty to stop or control worrying). Thereby this 4-item self-report questionnaire consists of two 2-item subscales, the depression scale PHQ-2 and the anxiety scale GAD-2 (General Anxiety Disorder-2). The PHQ-2 consists of two core criteria for depressive disorders. The GAD-2 consists of the two core criteria for generalized anxiety disorder that have also been shown to be good screening items for panic, social anxiety, and posttraumatic stress disorders. The questionnaire starts with the general question "Over the last two weeks, how often have you been bothered by the following problems?" and continues with asking for the four symptoms which are rated on a 4-point scale from 0 ('not at all') to 3 ('nearly every day'). The total sum score ranges from 0 to 12 with a range of 0 to 6 for each of the two subscales. An additional single item that is not included in any of the scale sum scores asks for the extent of the respondent's subjective psychosocial symptom-related impairment. A PHQ-2 score $\geq 3$ indicates clinically significant depression, and a GAD-2 score $\geq 3$ indicates clinically significant anxiety. A PHQ-4 total score cut-off point $\geq 6$ has been recommended as an indicator of the presence of a depressive or an anxiety disorder (Fröjd et al., 2007; Kerper et al., 2014). The validity and reliability of the instrument in Turkish was shown by Demirci et al. with an internal consistency reliability coefficient of 0.83 for overall scale (Khairandish et al., 2017).
Family APGAR is a brief screening questionnaire, which is designed to elicit a database that will reflect a patient's view of the functional state of his or her family. It will also discuss ways of assessing family resources and the use of a family problem-oriented record that may be used by the physician to improve family study, diagnosis, and management. It is a questionnaire that features five closed-ended questions, is introduced by the author as a screening test to give a rapid overview of the components of family function. The APGAR acronym has been applied since it is felt that the familiarity that physicians have with the Apgar evaluation of the newborn will encourage them to remember a similar format that scores the functional status of a family. Field tests with the Family APGAR are presently being conducted and early results are promising. The questions in the Family APGAR are designed to permit qualitative measurement of the family member's satisfaction with each of the five basic components of family function (Kocis, 1999; Kroenke et al., 2009). These components are described below:

Adaptation: How resources are shared, or the degree to which a member is satisfied with the assistance received when family resources are needed.

Partnership: How decisions are shared, or the member's satisfaction with mutuality in family communication and problem-solving.

Growth: How nurturing is shared, or the member's satisfaction with the freedom available within the family to change roles and attain physical and emotional growth or maturation.

Affection: How emotional experiences are shared, or the member's satisfaction with the intimacy and emotional interaction that exists in a family.

Resolve: How time (and space and money*) is shared, or the member's satisfaction with the time commitment that has been made to the family by its members (Kocis, 1999).

Permission for this study was granted by the local ethical committee. Informed consent was received from all patients and controls.

\subsection{Data analysis}

Statistical Package for Social Sciences Software (SPSS v.24, Chicago, IL, USA) was used for data analysis. Descriptive statics were used to describe the socio-demographic information of the study and control groups. The Student's ttest was used to compare the median of PHQ-4 and APGAR scores between the groups. Spearman correlation coefficients of subscale values were computed in order to quantify the strength of the relationship between the subscale scores of PHQ-4 and different dimensions of APGAR. The cut-off level for statistical significance was usually taken at 0.05 . In correlation analysis, a second cut-off was set at 0.01 . 


\section{Results}

In terms of gender distribution, the female gender was dominant in both groups and no difference was found in the comparison. $57 \%$ of the case group and $51 \%$ of the control group were female. The density of adolescents in middle adolescence was remarkable in both groups without any significant difference (Table 1).

Tablo 1. Distribution of groups by gender

\begin{tabular}{c|c|c|c|}
\hline Gender & Chest Pain & Control & $\mathbf{p}$ \\
\hline Male & 29 & 33 & $0.491^{*}$ \\
Female & 39 & 35 & \\
Total & 68 & 68 & \\
Age & $15.20 \pm 1.36$ & $15.04 \pm 1.34$ & $0.488^{* *}$ \\
*Student's t-test, ** Chi-square test & &
\end{tabular}

In the comparison of Patient Health Questionnaire-4 scale results, both the anxiety and depression subscale scores were higher in the non-cardiac chest pain group with a statistically significance (Table 2).

Table 2. Comparison of the patient health questionnaire-4 and family apgar scale total and subscale scores between the groups

\begin{tabular}{|c|c|c|c|}
\hline & $\begin{array}{l}\text { Chest Pain } \\
\text { (Mean } \pm \text { sd) }\end{array}$ & $\begin{array}{c}\text { Control } \\
(\text { Mean } \pm \text { sd) }\end{array}$ & p \\
\hline Anxiety & $2.58 \pm 1.69$ & $1.76 \pm 1.43$ & 0.003 \\
\hline Depression & $3.17 \pm 1.37$ & $2.14 \pm 0.99$ & $<0.001$ \\
\hline $\begin{array}{c}\text { PHQ Total } \\
\text { Score }\end{array}$ & $5.76 \pm 2.77$ & $3.91 \pm 2.06$ & $<0.001$ \\
\hline Adaptation & $1.16 \pm 0.66$ & $1.47 \pm 0.53$ & 0.003 \\
\hline Partnership & $0.85 \pm 0.65$ & $1.47 \pm 0.65$ & $<0.001$ \\
\hline Growth & $1.01 \pm 0.74$ & $1.42 \pm 0.63$ & 0.001 \\
\hline Affect & $0.88 \pm 0.56$ & $1.10 \pm 0.67$ & 0.040 \\
\hline Resolve & $1.05 \pm 0.64$ & $1.47 \pm 0.55$ & $<0.001$ \\
\hline $\begin{array}{c}\text { Total } \\
\text { APGAR } \\
\text { Score }\end{array}$ & $4.95 \pm 2.04$ & $6.94 \pm 1.62$ & $<0.001$ \\
\hline
\end{tabular}

*Student's t-test; PHQ: Patient Health Questionnaire; APGAR: Adaptation, Partnership, Growth, Affection, Resolve

With regard to the Spearman correlation analysis negative reciprocal relations were found between the PHQ-4 and Family APGAR subscale scores (Table 3).

\section{Discussion}

In the current study, anxiety, depression and all determinants of family functioning were found to be worse in the noncardiac chest pain group compared to the controls. Concerning the limited data in the literature, the adolescents with noncardiac chest pain have shown a significant breakdown considering mental health (Bolat et al., 2018, Lieb et al., 2007; Lipsitz et al., 2005; McFarlane et al., 1994). However, this is the first study that showed the impaired family functioning with a brief mental health screening in this clinical group.

Among our participants, the majority of adolescents with non-cardiac chest pain were female. It has been reported that somatic complaints and internalization problems are more common among girls than boys. There are only two studies on non-cardiac chest pain in the adolescent age group. In the first study, no difference was found between the genders, whereas in the second study, the excess female sex ratio was noteworthy (McFarlane et al., 1994; Messer and Gross, 1995).

The mean age of the patients with non-cardiac chest pain in our study was $15.2 \pm 1.36$ years and consisted mainly of the middle adolescence period. Adolescence period is divided into three as early adolescence (10-13 years), middle adolescence (14-16 years) and late adolescence (17-19 years). The psychosocial development of these three periods varies. In the middle adolescence, psychosocial development steps such as becoming emotionally independent from the family, the development of self-expression ability, and adopting traditional moral rules are accelerating. The problematic capacity of the adolescents to cope with the problems and the ability to respond to emotional problems may explain the increased incidence of non-cardiac chest pain in this group (Milov and Kantor, 1990).

In our study, anxiety, and depression symptoms were significantly higher in the non-cardiac chest pain group. The co-occurrence of depressive and anxiety disorders with somatic symptoms is associated with more functional disability, higher medical care use, and higher costs than the pathologies apart (Eliac1k et al., 2020; Ohayon and Schatzberg, 2003). In a study conducted in Iran, where the psychosocial status of all adolescent chest pains was examined without exclusion of organic causes, anxiety and depression levels have shown to be significantly different in almost all patients (Messer and Gross, 1995). Following this study in the literature, in a study conducted in our center where all organic causes were excluded, and only adolescents evaluated, we found that anxiety scores were slightly higher, but there were significantly higher depression scores and more suicidal thoughts (McFarlane et al., 1994). Somatic symptoms may mask depression and delay accurate diagnosis and treatment (Özcan et al., 2011). Moreover, somatic complaints appear to be predictors of poor prognosis in depression. Studies have shown that depressive individuals with physical symptoms tend to have a longer period of illness (Lee et al., 2013).

In our study, the Family APGAR scale scores evaluating the family functioning of adolescents were found to be significantly impaired in the non-cardiac chest pain group. A family is a psychosocial group consisting of the patient and one or more persons, children or adults, in which there is a commitment for members to nurture each other. To establish the parameters by which a family's functional health can be measured, five basic components of family function were chosen. These components appear to represent common themes in the social science literature that deals with families (Khairandish et al., 2017). Regarding the results of our correlation analysis between the PHQ-4 and the Family APGAR scores, perhaps unsurprisingly, all the family functioning subscale scores were in a negative correlation with anxiety and depression. 
Table 3. The reciprocal relation between the phq-4 and family apgar subscales scores

\begin{tabular}{|c|c|c|c|c|}
\hline & & phqtop & aa1 & aa2 \\
\hline \multirow{3}{*}{ phqtop } & Pearson Correlation & 1 & $-.438^{* *}$ & $-.419^{* *}$ \\
\hline & Sig. (2-tailed) & & .000 & .000 \\
\hline & $\mathrm{N}$ & 136 & 136 & 136 \\
\hline \multirow[t]{3}{*}{ aa1 } & Pearson Correlation & $-.438^{* *}$ & 1 & $.283^{* *}$ \\
\hline & Sig. (2-tailed) & .000 & & .001 \\
\hline & $\mathrm{N}$ & 136 & 136 & 136 \\
\hline \multirow[t]{3}{*}{$\overline{a a 2}$} & Pearson Correlation & $-.419^{* *}$ & $.283^{* *}$ & 1 \\
\hline & Sig. (2-tailed) & .000 & .001 & \\
\hline & $\mathrm{N}$ & 136 & 136 & 136 \\
\hline \multirow[t]{3}{*}{ aa3 } & Pearson Correlation & $-.381^{* *}$ & $.277^{* *}$ & $.202^{*}$ \\
\hline & Sig. (2-tailed) & .000 & .001 & .018 \\
\hline & $\mathrm{N}$ & 136 & 136 & 136 \\
\hline \multirow[t]{3}{*}{ aa4 } & Pearson Correlation & $-.287^{* *}$ & .083 & $.232^{* *}$ \\
\hline & Sig. (2-tailed) & .001 & .338 & .007 \\
\hline & $\mathrm{N}$ & 136 & 136 & 136 \\
\hline \multirow[t]{3}{*}{ aa5 } & Pearson Correlation & $-.481^{* *}$ & $.281^{* *}$ & $.358^{* *}$ \\
\hline & Sig. (2-tailed) & .000 & .001 & .000 \\
\hline & $\mathrm{N}$ & 135 & 135 & 135 \\
\hline \multirow[t]{3}{*}{ apgartop } & Pearson Correlation & $-.639^{* *}$ & $.601^{* *}$ & $.679^{* *}$ \\
\hline & Sig. (2-tailed) & .000 & .000 & .000 \\
\hline & $\mathrm{N}$ & 135 & 135 & 135 \\
\hline \multirow[t]{3}{*}{ anxiety } & Pearson Correlation & $.915^{* *}$ & $-.397^{* *}$ & $-.316^{* *}$ \\
\hline & Sig. (2-tailed) & .000 & .000 & .000 \\
\hline & $\mathrm{N}$ & 136 & 136 & 136 \\
\hline \multirow[t]{3}{*}{ collapse } & Pearson Correlation & $.865^{* *}$ & $-.383^{* *}$ & $-.446^{* *}$ \\
\hline & Sig. (2-tailed) & .000 & .000 & .000 \\
\hline & $\mathrm{N}$ & 136 & 136 & 136 \\
\hline
\end{tabular}

**, Correlation is significant at the 0.01 level (2-tailed); *, Correlation
Family functioning is disrupted in families of youth with elevated depressive symptomatology (Tunaoglu et al., 1995). In particular, depression appears to be associated with family environments characterized by an absence of supportive and facilitative interactions. The most widely reported finding is that depression is inversely related to the level of support and approval provided by the family environment. In observational studies of families with adolescent children, parents of depressed children displayed less positive, rewarding, and supportive behaviors than did parents in comparison families (Sartorius, 2003; Selbst, 2010).

Although thorough medical evaluation is appropriate and necessary in chest pain, ongoing tests or treatments are often not found to be beneficial after the absence of a medical etiology of pain, and even patients have the potential to raise serious illness concerns (Smilkstein, 1978). Therefore, the necessity of rapidly evaluating psychosocial health in adolescents with chest pain after the exclusion of organic causes was shown in this study.

This study had several important limitations to consider. First, the cross-sectional nature of the study prevented the ability to detect direct causal relationships between the variables. Although it was not evaluated in our study, the loss of labor of parents, anxiety that occurs in the parents, on the other hand, the transportation costs, frequent hospital admissions, and therefore high hospital costs are stated as significant losses in the unresolved chest pain (Kroenke et al., 2009). As these problems increased in this cycle, we suggested that family functioning may be adversely affected and may lead to a vicious cycle of non-cardiac chest pain. Second, this study obtained anxiety, depression, and family functioning

\begin{tabular}{|c|c|c|c|c|}
\hline $\mathbf{a a 3}$ & $\mathbf{a a 4}$ & $\mathbf{a a 5}$ & apgartop & anxiety \\
\hline$-.381^{* *}$ & $-.287^{* *}$ & $-.481^{* *}$ & $-.639^{* *}$ & $.915^{* *}$ \\
\hline .000 & .001 & .000 & .000 & .000 \\
\hline 136 & 136 & 135 & 135 & 136 \\
\hline $.277^{* *}$ & .083 & $.281^{* *}$ & $.601^{* *}$ & $-.397^{* *}$ \\
\hline .001 & .338 & .001 & .000 & .000 \\
\hline 136 & 136 & 135 & 135 & 136 \\
\hline $.202^{*}$ & $.232^{* *}$ & $.358^{* *}$ & $.679^{* *}$ & $-.316^{* *}$ \\
\hline .018 & .007 & .000 & .000 & .000 \\
\hline 136 & 136 & 135 & 135 & 136 \\
\hline 1 & .152 & $.315^{* *}$ & $.639^{* *}$ & $-.340^{* *}$ \\
\hline & .077 & .000 & .000 & .000 \\
\hline 136 & 136 & 135 & 135 & 136 \\
\hline 152 & 1 & $.226^{* *}$ & $.533^{* *}$ & $-.225^{* *}$ \\
.077 & & .009 & .000 & .008 \\
\hline 136 & 136 & 135 & 135 & 136 \\
\hline $.315^{* *}$ & $.226^{* *}$ & 1 & $.687^{* *}$ & $-.409^{* *}$ \\
\hline .000 & .009 & & .000 & .000 \\
\hline 135 & 135 & 135 & 135 & 135 \\
\hline $639^{* *}$ & $.533^{* *}$ & $.687^{* *}$ & 1 & $-.537^{* *}$ \\
\hline .000 & .000 & .000 & & .000 \\
\hline 135 & 135 & 135 & 135 & 135 \\
\hline. $.340^{* *}$ & $-.225^{* *}$ & $-.409^{* *}$ & $-.537^{* *}$ & 1 \\
\hline .000 & .008 & .000 & .000 & 136 \\
\hline 136 & 136 & 135 & 135 & $.588^{* *}$ \\
\hline $.340^{* *}$ & $-.294^{* *}$ & $-.455^{* *}$ & $-.613^{* *}$ & .000 \\
\hline .000 & .001 & .000 & .000 & 136 \\
\hline 136 & 136 & 135 & 135 & \\
\hline
\end{tabular}

significant at the 0.05 level (2-tailed)

scores based on self-report questionnaires, which may be subject to bias due to patient self-concept and perception. However, the value of PHQ-4 and Family APGAR scales are largely related to the perception of the individual, and therefore this limitation should not impact findings given the value of understanding one's own report of mental health and family functioning. To shed more light on adolescent chest pain, which is a common cause of hospital admissions, longitudinal, prospective studies are needed. Other social problems (absenteeism, stigmatization in the form of heart disease, the financial loss experienced by the family, and the cost of social security institution due to frequent visits to the cardiology outpatient clinic), which did not include in this study, may be the subject of future studies.

The results of the study indicated a strong association between anxiety, depression, impaired family dysfunction, and adolescent non-cardiac chest pain. Since chest pain is a common referral to pediatric health services, there is a need for a brief psychosocial evaluation that comprised of mental health screening and family functioning that will prevent unnecessary medical investigations and expenses. The results suggested a need of a collaboration between pediatric emergency physicians, pediatric cardiologists, pediatricians, adolescents medicine physicians and psychiatrists for the adolescent noncardiac chest pain.

\section{Conflict of interest}

None of the authors have any conflict of interest.

\section{Acknowledgments}

None to declare. 


\section{References}

1. Avison, W.R., McAlpine, D.D., 1992. Gender differences in symptoms of depression among adolescents. J. Health Soc. Behav. 77-96.

2. Bass, C., Wade, C., 1984. Chest pain with normal coronary arteries: a comparative study of psychiatric and social morbidity. Psychol. Me. 14, 51-61.

3. Bass, C., Mayou, R., 2002. Chest pain. BMJ. 325, 588-591.

4. Bekhuis, E., et al., 2015. Differential associations of specific depressive and anxiety disorders with somatic symptoms. J. Psychosom. Res. 78, 116-122.

5. Bolat, N., et al., 2018. Adolescent mental health, attachment characteristics, and unexplained chest pain: a case control study. Psyc. Clin. Psychopharm. 29, 487-491.

6. Cole, D.A., Rehm, L.P., 1986. Family interaction patterns and childhood depression. J. Abnor Child. Psychol. 14, 297-314.

7. Demircia, İ., Ekşib, H., 2018. Don't bother your pretty little head otherwise you can't enjoy life. ERPA. 2018. 287.

8. Eliacik, K., et al., 2017. Anxiety, depression, suicidal ideation, and stressful life events in non-cardiac adolescent chest pain: a comparative study about the hidden part of the iceberg. Cardiol. Young. 27, 1098-1103.

9. Eliacik, K., et al., 2020. Adolescent with unexplained chest pain reported depression and impaired emotional and social functioning. Acta Pediatrica, 109, 1642-1648.

10. Eslick, G.D., Jones, M.P., Talley, N., 2003. Non-cardiac chest pain: prevalence, risk factors, impact and consulting a population-based study. Aliment. Pharmacol. Ther. 17, 11151124.

11. Fröjd, S., Kaltiala-Heino, R., Rimpelä, M., 2007. The association of parental monitoring and family structure with diverse maladjustment outcomes in middle adolescent boys and girls. Nord. J. Psychiatry. 61, 296-303.

12. Juli-anne, K.E., Parsons, M., Renneburg, A.K., 2000. Chest pain in children: Diagnosis through history and physical examination. J. Pediatr. Health Care. 14, 3-8.

13. Kerper, L., et al., 2014. Screening for depression, anxiety and general psychological distress in preoperative surgical patients: A psychometric analysis of the Patient Health Questionnaire 4 (PHQ-4). Clin. Health. Promot. 4, 5-14.

14. Khairandish, Z., Jamali, L., Haghbin, S., 2017. Role of anxiety and depression in adolescents with chest pain referred to a cardiology clinic. Cardiol. Young. 27, 125-130.

15. Kocis, K.C., 1999. Chest pain in pediatrics. Pediatr. Clin. N. Am. 46, 189-203.

16. Kroenke, K., et al., 2009. An ultra-brief screening scale for anxiety and depression: the PHQ-4. Psychosomatics. 50, 613621.

17. Lee JL, Gilleland J, Campbell RM, Simpson P, Johnson GL, Dooley KJ, Blount RL. Health care utilization and psychosocial factors in pediatric noncardiac chest pain. Health Psychol. 2013;32(3), 320-327.

18. Lieb, R., Meinlschmidt, G., Araya, R., 2007. Epidemiology of the association between somatoform disorders and anxiety and depressive disorders: an update. Psychosom. Med. 69, 860-863.

19. Lipsitz, J.D., et al., 2005. Noncardiac chest pain and psychopathology in children and adolescents. J. Psychosom. Res. 59, 185-188.

20. Messer, S.C., Gross, A.M., 1995. Childhood depression and family interaction: A naturalistic observation study. J. Clin. Child Psychol. 24, 77-88.

21. McFarlane, A.H., et al., 1994. Adolescent depression in a schoolbased community sample: Preliminary findings on contributing social factors. J. Youth Adolesc. 23, 601-620.

22. Milov, D.E., Kantor, R.J., 1990. Chest pain in teenagers: When is it significant? Postgrad. Med. 88, 145-154.

23. Ohayon, M.M., Schatzberg, A.F., 2003. Using chronic pain to predict depressive morbidity in the general population. Arch. Gen. Psychiatry. 60, 39-47.

24. Özcan, S., Duyan, V., İncecik, Y., 2011. Aile Hekimliği'nde Aile APGAR Ölçeği'nin Kullanımı: Türkçeye Uyarlama Çalışması. The Journal of Turkish Family Physician. 2, 30-37.

25. Sartorius, N., 2003. Physical symptoms of depression as a public health concern. J. Clin. Psychiatry. 64, 3-4.

26. Selbst, S.M., 2010. Approach to the child with chest pain. Pediatric Clinics. 57, 1221-1234.

27. Smilkstein, G., 1978. The family APGAR: a proposal for a family function test and its use by physicians. J. Fam. Pract. 6, 1231-1239.

28. Tunaoglu, F., et al., 1995. Chest pain in children referred to a cardiology clinic. Pediatr. Cardiol. 16, 69-72. 